\title{
Erratum to: Credit Risk Management: Pricing, Measurement, and Modeling
}

Erratum to:

(C) Springer International Publishing AG 2017

J. Witzany, Credit Risk Management, DOI 10.1007/978-3-319-49800-3

1. The below given paragraph was placed in a separate page previously. This has been now placed at the end of preface:

This book has been also supported by the V̌́E

institutional grant IP100040 and by the

Czech Science Foundation Grant 15-00036S,

"Credit Risk Modeling for Financial and

Commodity Assets Portfolios."

2. Inadvertently the "Literature section" (list of references) in the Back matter of this book was not included originally. It has now been included.

The updated original online version for this book can be found at

DOI 10.1007/978-3-319-49800-3 